ANALES DE LA UNIVERSIDAD DE ALICANTE. HISTORIA MEDIEVAL, n. ${ }^{\circ} 20$ (2017-2018): 187-209

DOI:10.14198/medieval.2017-2018.20.07 I.S.S.N.: 0212-2480

Puede citar este artículo como:

de la Cruz Palma, Óscar. «La retórica de la concordia y de la tolerancia con el islam: una nueva frontera». Anales de la Universidad de Alicante. Historia Medieval, N. 20 (2017-2018): 187-209, DOI:10.14198/medieval.2017-2018.20.07

\title{
LA RETÓRICA DE LA CONCORDIA Y DE LA TOLERANCIA CON EL ISLAM: UNA NUEVA FRONTERA*
}

Óscar de la Cruz Palma Universidad Autónoma de Barcelona

\section{RESUMEN}

La victoria de los turcos sobre Constantinopla en 1453 confirmó al enemigo sarraceno como la potencia dominante en el Mediterráneo oriental. Tras siglos de denostación del islam y de acciones bélicas y de cruzadas, ahora el occidente cristiano debía poner en marcha un sistema diplomático que permitiera mantener relaciones internacionales con el poderoso mundo islámico. En estas circunstancias, las artes (y no sólo la literatura) se volvieron a mostrar como un instrumento útil para reconstruir estas relaciones diplomáticas. La retórica basada en la idea de concordia y tolerancia se ofreció entonces como un instrumento muy eficaz; sin embargo, lejos de aproximar a los pueblos y construir una sola nación de pueblos, realmente la nueva retórica servía para construir una frontera entre enemigos que debían respetarse y mantener las distancias.

Palabras clave: Tolerancia religiosa, literatura de controversia con el islam, diálogo interreligioso, traducciones latinas del Corán.

* Este trabajo ha sido elaborado en el marco del proyecto de investigación "La percepción del Islam en la Europa cristiana. Traducciones latinas del Corán y controversias islamo-cristianas", FFI2008-06919-C02-02/FILO del SPGPI-MICINN y del projecte de recerca consolidat SG 00824 de la AGAUR-Generalitat de Catalunya, dirigidos por el Dr. José Martínez Gázquez. 


\section{SUMMARY}

The victory of the Turks over Constantinople in 1453 confirmed the Saracen enemy as the dominant power in the eastern Mediterranean. After centuries of Muslim vilification, warfare and crusades, the Christian West now had to establish a diplomatic system that would maintain international relations with the powerful Muslim world. Under these circumstances, the arts (and not just literature) proved once again to be a useful instrument to rebuild these diplomatic relations. A rhetoric based on mutual understanding and tolerance was then advanced as a highly effective tool; however, far from bringing people closer and building a single nation of peoples, the new rhetoric actually led to constructing a frontier between enemies that had to be respected and that maintained distances between them.

Keywords: Religious tolerance, literature on controversy with Islam, interreligious dialogue, Latin translations of the Koran.

\section{PRELIMINAR}

Nuestra hipótesis aquí es que la idea de concordia y de tolerancia, refiriéndonos a la aproximación entre religiones, especialmente entre cristianismo e islam, configura un tipo de frontera: la retórica que las justifica va encaminada a construir una frontera intelectual que acompaña a las fronteras políticas entre las naciones en conflicto o entre los grupos sociales en contacto.

Ahora bien, para establecer la "frontera" retórica de la concordia, hace falta haber renunciado a la conquista o a la cruzada y reconocer la frontera política. En relación con el islam, ello sucede con claridad a partir de la caída de Constantinopla en manos de los turcos, en 1453, cuando se da una renuncia expresa a la recuperación del territorio que ahora ha caído en manos de los musulmanes turco-otomanos. Y por el mismo motivo, esta retórica de la concordia no aparece en territorio peninsular durante el siglo XV, habida cuenta que sólo a partir del 1492 se considera vencido el islam. En este período quizás sólo cabe salvar a Juan de Segobia, que propugna una contraferentia para llegar a salvar las diferencias, aunque escribe desde la Savoya francesa y está siendo influenciado por los intereses italianos, que miraban más hacia el Levante mediterráneo que hacia el sur peninsular. Y la retórica de la concordia es difícil de hallar en autores hispanos durante el siglo XVI y XVII, pues la presencia islámica está sometida al poder cristiano y tal retórica resulta menos necesaria que la de la conversión y, como se sabe, la de expulsión. 
Es entonces respecto al avance turco y a la fecha indicada cuando aparece en la literatura europea con más fuerza la retórica de la concordia, ahora ya incluso en los títulos de algunas obras, como una innovación que no debe sorprender: así sucede en el De pace fidei de Nicolás de Cusa, escrito en el mismo año de la caída de Constantinopla, o en el De orbis terrae concordia de Guillaume Postel, impreso exactamente cien años más tarde, en 1543-1544¹.

Después de siglos de enfrentamientos militares con el avance musulmán y de haber redactado una literatura antiislámica sobradamente ardua y denigratoria, se hacía difícil restituir las relaciones, pues los argumentos de denostación habrían sentado unas bases contrarias al nuevo objetivo de reconocimiento de la frontera con el poder otomano. Serán más útiles para construir la nueva retórica de la concordia aquellos autores que con más claridad habían renunciado al éxito de las armas y habían promulgado la aproximación a través de la palabra, aunque hay que reconocer que siempre con voluntad de dominio del cristianismo sobre el resto de religiones. De ahí que a partir del siglo XV se mantendrán más vivos y se preferirán los discursos de autores que habían hablado de aproximación al islam, desde Pedro el Venerable hasta algunos de los dominicos y franciscanos mejor informados sobre el islam, como Riccoldo de Monte Croce y Ramon Llull.

Para que nuestra hipótesis sobre la aparición de la retórica de la concordia sea sostenible es necesario reconocer que las relaciones entre el mundo cristiano y musulmán durante la Edad Media marcan la trayectoria de las relaciones posteriores de época moderna, toda vez que el enemigo musulmán es primero el árabe-bereber y luego el turco, es decir dos mundos islámicos de naturaleza diferente, aunque mejor diferenciados en occidente muy recientemente. Y también hay que observar que las relaciones entre el mundo cristiano y musulmán resultan complejas, dado que se reconocen varios niveles en los que las consideraciones llegan a ser contradictorias: ante la admiración por la sabiduría árabe y reconocimiento de la propia ignorancia de los cristianos (J. Martínez Gázquez 2007), hay que recordar el desarrollo de las Cruzadas y el sentimento de superioridad del mundo cristiano; y que dentro de una amplia literatura de denostación del islam, la tradición cristiana reconoció positivamente ciertas costumbres islámicas y que el islam ostentaba ciertas verdades aceptables teológicamente por el cristianismo. Esta

1 Esta obra fue impresa en Basilea por Johannes Oporinus, pero sine anno. Los datos del contexto biográfico y bibliográfico permiten fijar que la obra se habría imprimido en 1543 o, más bien, en 1544. Sabemos que Postel quiso verla publicada en 1543, justo cien años después de la caída de Constantinopla. Para la cuestión, O. de la Cruz (2011, en prensa). 
doble relación hacia el islam de admiración y denostación hace compleja la comprensión de las relaciones entre ambos bandos, toda vez que permitirá que, en base a los antecedentes más positivos, el mundo occidental irá construyendo el discurso de la relaciones diplomáticas con el islam y, por lo tanto, de la tolerancia, marcado por la necesidad de señalar la frontera política.

\section{ANTECEDENTES}

Para encontrar una retórica de acercamiento hacia el islam en la literatura medieval hay que esperar hasta el siglo XII. La hallamos en las obras del abad de Cluny, Pedro el Venerable (c. 1092-1156). De manera insólita hasta entonces, en su tratado Liber contra sectam siue haeresim Sarracenorum (R. Glei, 1985), compuesto hacia el final de su vida, se dirige a los musulmanes para que reconsideren los errores de sus doctrinas. Su retórica de acercamiento, aun así, va encajada en una inteligentísima retórica de polémica y beligerancia. Por ejemplo, el inicio del libro I:

$<23>$ In nomine Patris et Filii et Spiritus Sancti, unius omnipotentis et veri dei, Petrus quidam, Gallus natione, Christianus fide, abbas officio eorum qui monachi dicuntur, Arabibus Ismaelis filiis legem illius qui Mahumetus dicitur servantibus.

$<24>$ Mirum videtur et fortassis etiam est, quod homo a vobis loco remotissimus, lingua diversus, professione seiunctus, moribus vitaque alienus, ab ultimis Occidentis hominibus in Orientis vel meridiei partibus positis scribo, et quos numquam vidi, quos numquam forte visurus sum, loquendo aggredior. Aggredior inquam vos, non, ut nostri saepe faciunt, armis sed verbis, non vi sed ratione, non odio sed amore.

$<23>$ En el nombre del Padre y del Hijo y del Espíritu Santo, del único omnipotente y verdadero Dios, un tal Pedro de nación gala, de fe cristiana, de oficio abad de aquellos que se llaman monjes se dirige a los árabes hijos de Ismael que preservan la ley de aquel que se llama Mahoma.

$<24>$ Parece admirable, y quizás ciertamente lo es, que siendo yo un hombre tan alejado de vosotros en la distancia, con una lengua diferente, con una profesión distinta, estraño por las costumbre y vida, escriba desde los extremos de occidente a hombres ubicados en las partes de oriente y del sur, y que por la palabra me dirija a los que nunca he visto, a los que quizás nunca veré. Me dirijo, digo, a vosotros, no con las armas, como los nuestros hacen a menudo, sino con las palabras; no con la fuerza, sino con la razón; no con odio, sino con amor. (traducción propia).

Desde el prólogo, en el que muestra una retórica de búsqueda de concordia al apelar al amor en lugar de a las armas, Pedro el Venerable ejecuta una idea que ya venía reclamando años atrás: la necesidad de refutar racio- 
nalmente y, por lo tanto, de manera definitiva el islam. Lo mismo hace explícito en su tratado anterior, como desideratum en la conclusión de su Summa quaedam breuis contra haereses et sectam Sarracenorum siue Ismaelitarum (ed. R. Glei, 1985):

$<18>$ Nam et haec tota causa fuit, qua ego Petrus sanctae Cluniacensis ecclesiae humilis abbas, cum in Hispaniis pro uisitatione locorum nostrorum quae ibi sunt, demorarer, magno studio et impensis totam impiam sectam, eiusque pessimi inuentoris execrabilem uitam, de Arabico in Latinum transferri, ac denudatam ad nostrorum noticiam uenire feci, ut quam spurca et friuola heresis esset sciretur, et aliquis Dei seruus, ad eam scripto refellendam, Sancto inflemmante Spiritu incitaretur. Quod quia proh dolor, iam paene toto huiusmodi studiorum sanctorum ubique in ecclesia tepefacto feruore, non est qui faciat, expectaui enim diu, et non fuit qui aperiret os et zelo sanctae Christianitatis moueret pennam et ganniret, ego ipse saltem, si magnae occupationes meae permiserint, quandoque id aggredi Domino adiuuante proposui. Semper tamen a quocumque altero melius, quam a me deterius hoc fieri, gratum haberem. Explicit.

$<18>$ Y esta fue toda la razón por la cual yo, Pedro, humilde abad de la santa iglesia de Cluny, cuando estaba en Hispania de visita a nuestros lugares que hay allí, con gran empeño y gasto hice traducir del árabe al latín toda aquella impía secta y la execrable vida de su pésimo inventor ${ }^{2}$, y la hice llegar, comprensible, al conocimiento de los nuestros, para que se sepa cuán sucia y frívola es esta herejía, y para que algún servidor de Dios, con la inspiración del Espíritu santo, se anime a refutarla por escrito. Porque, ay dolor, ya casi acabado el fervor que hay por doquier de la Iglesia por este tipo de santos eruditos, como que no hay quien lo haga, y como que esperé mucho tiempo y no hubo quien abriera la boca ni, por celo de la santa cristiandad, moviera la pluma y gritara, por lo menos yo mismo, si me lo permitieran mis grandes ocupaciones, me propuse cumplirlo en algún momento, con la ayuda del Señor. Pero siempre tendría como cosa grata que esta refutación fuera mejor hecha por cualquier otro que mal por mí. (traducción propia).

Cumpliendo lo anunciado en el prólogo de su Liber contra sectam, Pedro el Venerable, acude a la metáfora de la contienda dialéctica, construyendo la imagen del campo de batalla durante su discurso. Así en LS 87 (ed. R. Glei, 1985):

$<87>$ Ea de causa vos praemonitos et praemunitos esse denuntio, quod, ubi in processu propositi operis et sermonis oportunum fuerit, ex his quae iam necessario ut divina tenetis vos aggrediar, et sicut ex concessis fieri ratio disputandi suadet, falsitatem qua exceptis Iudaeis prae cunctis mortalibus

2 Es decir, la traducción del Corán, de la vida de Mahoma y de la doctrina islámica dados en la Chronica mendosa, el Liber de generatione Mahumet y el Liber de doctrina Mahumet, traducidos entre finales de 1142 e inicios de 1143. 
irretiti et obruti estis, ut potero impugnabo et scuto veritatis protectus deo iuvante pro viribus expugnabo.

$<87>$ Por este motivo os aviso que estáis advertidos y avisados de que, cuando sea oportuno durante el análisis de la obra y discurso propuesto, me enfrentaré a vosotros partiendo de la base de aquello que, ya por necesidad, tenéis como divino, y, tal como el tema de la discusión aconseja hacer a partir de los puntos concedidos, atacaré todo lo que pueda la falsedad en la que, más que todos los otros mortales, excepto los judíos, estáis enredados y recubiertos; y, protegido con el escudo de la verdad, os venceré con la ayuda que Dios da a los hombres. (traducción propia)

y en LS 89 -ahora en el inicio del libro II- (R. Glei, 1985):

$<89>$ Iam quia, o Ismaelitae, praemissis quae praemittenda erant contra summum religionis vestrae robur agendum est, continere ut praemonui gladios, seponite lapides, aperite aures, et si quid prudentiae saltem humanae in vobis est, deposito pertinaci ac puerili vincendi studio intentis animis quae sequuntur audite. Vtile potuerit hoc esse vobis.

$<89>$ Ismaelitas, una vez han avanzado las razones que tenían que avanzar, hay que ir contra la máxima fuerza de vuestra religión: guardad, como dije [LS 44 y 50, ed. R. Glei, 1985], las espadas, dejad las piedras, abrid los oídos y, si tenéis por lo menos un poco de prudencia humana, una vez abandonado el pertinaz y pueril empeño de ganar, escuchad con ánimos atentos lo que sigue. Os podría ser útil. (traducción propia).

Bastan los ejemplos de la retórica empleada por Pedro el Venerable para comprender el alcance de las palabras citadas del inicio de su libro I (LS, 24, cit.): "Me dirijo, digo, a vosotros, no con las armas, como los nuestros hacen a menudo, sino con las palabras; no con la fuerza, sino con la razón; no con odio, sino con amor". Sin dudar de sus intenciones y aun reconociendo la voluntad de vencer por la retórica y no por las armas, la beligerancia se hace patente en su obra y el tono de polémica concuerda con las circunstancias de Cruzada, perdiendo así la oportunidad de considerarlas un gesto sincero de concordia para ser reconocidas como un nuevo intento de victoria sobre el islam, eso sí, con argumentos razonados y basados en las Escrituras.

Es cierto que cuando Pedro el Venerable escribe con esta intención y tono ya existe una literatura de refutación del islam; pero ésta nunca se había ofrecido en clave de aproximación directa (LS I, 24 cit.: "Parece admirable, y quizás ciertamente lo es (...), que por la palabra me dirija a los que nunca he visto, a los que quizás nunca veré"). Pocos años antes, Pedro Alfonso de Huesca (1062-1135) se había referido al islam en el capítulo V de su obra Dialogus contra Iudaeos (M.J. Lacarra, 1996) con un cierto reconocimiento a costumbres y dogmas aceptables de los sarracenos. Pero el texto reproduce 
un diálogo ficticio entre el judío Moisés y el cristiano Pedro (ambos representando al mismo autor, antes y después de su conversión del judaísmo al cristianismo), sin la interpelación directa de un musulmán.

Además, contemporáneamente al abad de Cluny y anteriormente, sobre todo en relación con la primera cruzada, hay que contrastar una cierta producción de ridiculización y denostación del islam, en el que no cabe la más mínima atención de reconocimiento al mismo. Así, los poemas de Émbrico de Mainz, Carmen de fraudibus Mahumetis (ed. Migne PL 171) y de Gautier de Compiègne, Otia de Machomete (ed. E. du Meril, 1847), junto a las alusiones denigratorias del islam y del Profeta Muhammad en otras tantas obras aparecidas desde el siglo VIII.

Después del abad de Cluny, los hermanos dominicos y, sobre todo, franciscanos dieron un paso adelante en la búsqueda de la concordia a partir de mediados del siglo XIII. Sus nuevas estrategias de conversión mediante la predicación y, sobre todo, de la búsqueda del contacto directo con el islam, siguiendo el modelo de san Francisco de Asís (J. Tolan, 2007), favorecieron la introducción de información directa de las fuentes árabes y, por lo tanto, de noticias que permitían refutar el islam de manera mucho más matizada de lo que lo había hecho la tradición. Por ejemplo, está claro que en el siglo XIII el mundo cristiano europeo ya había comprendido que el islam estaba compuesto por varias "confesiones" diferentes, y que existían divergencias internas en cuanto a la interpretación de las doctrinas islámicas.

El primer caso, el de Ramon Llull (1232-1316), es muy explícito y signficativo. Así, por ejemplo, su conocimiento del islam es altísimo y complejo, muy apegado a la realidad, como resulta evidente de lo que refiere en su Llibre del gentil e dels tres savis IV, 13, compuesto hacia 1272.

[Solució]. Respós lo sarraý e dix: -Veritat es que enfre nos som diverses a creure la gloria de paraýs, cos los uns la creen aver segons que yo t'e recomtat; e asó entenen segons espusició literal, la qual prenen de l'Alcorá, qui es nostra lig, e de los Proverbis de Mafumet, e de les gloses dels esponedors del Alcorá e dels Proverbis. Mas altres jents son enffre nos qui entenen la gloria moralment, e esponen-la speritualment, e dien que Maffumet parlava per semblanssa a les gents qui eren pegues e sens enteniment; e per so que.ls pogués enamorar de Deu, lur recomtava la gloria damunt dita [sc. del Paraíso]. E per asó aquells qui an a aquesta creenssa dien que en paraýs no aurá gloria de menjar ni de jaer ab ffembra ni de les altres coses damunt dites. E aquests aytals son naturals e grans clergues, e son homens qui en alcunes coses no sserven be los manaments de la ley nostra, e per asó nos los avem enffre nos quaix a eretges, a la qual eretgia son venguts per oyr logica e natures. E per asó es fet establiment enffre nosaltres que publicament null hom no gos legir logica ni natures. (ed. A. Bonner, 2001²) 
En varios lugares del Libre del gentil, Ramon Llull hace explícito su deseo de concordia hominum: por citar un ejemplo, Ramon Llull, Libre del gentil IV, epil. (ed. A. Bonner 2001², p.209):

Cascú dels iii. savis tenc per bo so que.l savy deya, e hordonaren lo loc e la ora on s'esputassen, e la manera con s'onrasen e.s servissen e s'esputassen. E con se serien concordats e avenguts en .ia. ffe, que anasen per lo mon donant gloria e laor del nom de nostre senyer Deus.

Hay que recordar, sin embargo, que en otras obras posteriores el tono de Ramon Llull hacia el islam se muestra tan crudo y beligerante como el que se había producido generalmente en la tradición medieval, como ocurre en el Liber de fine (1305, ed. de A. Madre, 1981, ROL IX) o en el Liber disputationis Raimundi christiani et Homeri sarraceni (1308, ed. de A. Madre, 1998, ROL XXII) (O. de la Cruz, 2008), aun sin dejar de reconocer que en estos libros la información que demuestra conocer Ramon Llull sobre el islam es extraordinaria, siendo el único que da ciertas noticias en toda la tradición europea medieval.

Antes de dejar de lado el caso de Ramon Llull creemos importante señalar que éste comprendió que las diferencias doctrinales entre el cristianismo y el islam residían en dos dogmas: la Trinidad y la Encarnación. Las demás diferencias eran salvables y tolerables, siempre en pos del fin último o primera entenció que debe tener el hombre, es decir amar y reconocer a Dios. Su famosa lógica expresada en su compleja ars lulliana y también su proyecto de conversión del islam no son más que métodos para alcanzar tal fin, y para que sea posible el hombre requiere la paz social, es decir, conseguir una ciuitas mundi sin conflictos que lo impidan (O. de la Cruz, 2008). Su definición en el Liber de ciuitate mundi (1314, ed. J. Stöhr 1960, ROL II, 169-201) es significativa para nuestro caso, pues para Ramon Llull la ciuitas mundi es, en cierto sentido, el mundo:

Ciuitas est locus hominum, in quo intellectus humanus habituat se ipsum de scientia liberali et mechanica; cum quibus acquirat ea, quae sunt sibi necessaria ad bene uiuendum, ut attingat finem, quare creatus est (Liber de ciuitate mundi, ROL II, 173.)

La ciudad es el espacio de los hombres, en el cual el intelecto humano se ejercita a sí mismo en la ciencia liberal y mecánica, con las cuales pueda adquirir aquello que le es necesario para vivir bien, con la finalidad de que consiga el fin para el que ha sido creado. (trad. propia)

Estrictamente contemporáneo a Ramon Llull hallamos al dominico Riccoldo de Monte Croce (c. 1243-1320). Aunque no llega a postular la idea de tolerancia o de concordia expressis uerbis, lo cierto es que no es difícil 
encontrar en sus obras referencias muy positivas hacia el islam. Tras varios años en oriente, (entre 1272-1296), en Bagdad tuvo ocasión de estudiar la lengua árabe y la cultura islámica, y desde esta ciudad mantuvo una cierta correspondencia en la que hace valiosas evaluaciones sobre las comunidades cristianas en la zona y sobre la caída de San Juan de Acre (18 de mayo de 1291), acontecimiento que conmovió a occidente y que marcó un límite a las pretensiones europeas por la recuperación de Tierra Santa.

De vuelta a Florencia, compuso sus tratados dirigidos a la refutación del islam, pero en los que la experiencia del viaje (itinerarium) y del contacto directo aportan una información extraordinaria para el momento. Su descripción de las costumbres de los Sarracenos dentro de su tratado Liber peregrinationis, compuesto en $1300^{3}$, parte de una clara intención de desterrar los prejuicios (confusionem) que mantienen los cristianos, en donde reconoce la concordia de la que son capaces:(ed. R. Kappler, 1997, p. 158)

$<2>$ Opera perfectionis Sarracenorum

Referemus igitur hic breuiter quedam opera perfectionis Sarracenorum magis ad confusionem Christianorum quam ad commendationem Sarracenorum. Quis non obstupescat si diligenter consideret quanta est ipsis Sarracenis sollicitudo ad studium - deuotio in oratione - misericordia ad pauperes - reuerentia ad nomen Dei et prophetas et loca sancta - grauitas in moribus - affabilitas ad extraneos - concordia et amor ad suos.

$<2>$ Obras de perfección de los Sarracenos

Así pues referiremos ahora brevemente algunas obras de perfección de los Sarracenos, más de cara a la confusión de los cristianos que al elogio de los Sarracenos. ¿Quién no se sorprenderá si considerara diligentemente cuánta es la entrega al estudio entre los mismos Sarracenos, su devoción en la oración, su misericordia hacia los pobres, su reverencia hacia el nombre de Dios y hacia los profetas y lugares santos, su gravedad en las costumbres, su afabilidad hacia los extranjeros y su concordia y amor hacia los suyos? (trad. propia).

Sobre todo, lo que a Riccoldo le interesa demostrar es la superioridad de la Biblia sobre el Corán, pero es capaz de reconocer que hay bastantes prácticas loables en el Islam. Así, por ejemplo, (ed. R. Kappler, 1997, p. 164):

3 Conocemos las ediciones siguientes: R. KAPPLER (1997), Riccold de Monte Croce. Pérégrination en Terre Sainte et au Proche Orient (texto latino y trad. franc.). Lettres sur la chute de Saint-Jean d'Acre (trad. franc.) Paris. - J.C.M. LAURENT (1873²), Peregrinationes Medii Aeui Quatuor, Lipsiae (ed. a partir del manuscrito de Berlin) - U. MONNERET DE VILLARD (1948), Il libro della peregrinazione nelle parti d'Oriente di Frate Ricoldo da Montecroce, Roma, Istituto Storico Domenicano S. Sabina. 
$<6>$ De reuerentia ad nomen Dei

Reuerentiam uero maximam habent ad nomen Dei et prophetas et sanctos et loca sancta. Nam hoc maxime obseruant quod nichil notabile faciunt uel dicunt, uel scribunt quod non incipiant a nomine Dei. Vnde in suis litteris omnibus quas sibi inuicem mittunt reuerenter nomen Domini prius scribunt et idoe diligenter osserunat quod nullum scriptum dilanient uel in terram prohiciant. Si autem in terra inueniunt aliquid de carta scriptum reuerenter recolligunt et ponunt in loco alto in fixuris murorum ne nomen Domini conculcetur. Quando autem occurrit nomen Domini uel legendo uel loquendo nunquam esset ausus ipsum nominare solum sed semper cum certa laude scilicet Deus laudetur ipse uel aliquid tale. Si quis autem Sarracenus Deum uel aliquem de prophetis eius blasfemaret nunquam eum uiuere paterentur. Loca uero sancta sicut suas ecclesias semper mundissima seruant nec ibi intrant nisi pedibus discalciatis.

$<6>$ Sobre la reverencia al nombre de Dios

(Los sarracenos) tienen la máxima reverencia hacia el nombre de Dios, los profetas, los santos y los lugares santos. Y ello lo observan tanto que no hacen o dicen nada notable o no escriben nada que no inicie con el nombre de Dios. De ahí que en todas las cartas que se envían entre ellos de manera reverente escriben primero el nombre del Señor y por ello diligentemente cuidan que ningún escrito se pierda o se tire al suelo, y si encuentran en el suelo algo escrito de una carta, lo recogen y lo colocan en un lugar alto, en las endiduras de los muros, para que el nombre del Señor no sufra desprecio. Y cuando aparece el nombre del Señor leyendo o hablando, nunca osan nombrarlo solo, sino que siempre va acompañado de algún elogio, como "que Dios sea loado" o a algo semejante. Si algún sarraceno blasfemara a Dios o alguno de los profetas, nunca se mantendría en vida. Conservan sus lugares santos como sus iglesias siempre limpísimas, y no entran si no es con los pies descalzos. (trad. propia)

El contra legem Sarracenorum, compuesto también hacia 1300 a posteriori de su estancia en el Próximo Oriente, y en el que Riccoldo no deja igualmente de hacer referencias de reconocimento hacia las costumbres de los musulmanes, tuvo un enorme éxito y difusión. En 1385 el bizantino Demetrio Cidones lo tradujo al griego, a partir de cuya versión fue retraducido al latín por Bartolomeo Piceno de Montearduo, que trastocó el nombre del autor por Richardus, en lugar de Riccoldus. Antonio de la Peña edita esta obra en 1500 en Sevilla, y en 1542 se edita la versión alemana elaborada por Lutero. El año siguiente, Bibliander incluye la versión de Montearduo en su famosa collectio. 


\section{A PARTIR DE LA CAÍDA DE CONSTANTINOPLA}

Cuando llegó a occidente la noticia de la caída de Constantinopla en manos de los turcos, el fatídico 29 de mayo de 1453, las reacciones fueron múltiples. Casi todas se referían al acontecimiento de manera lamentable. De tales reacciones (A. Pertusi, 1976; P. Bádenas - I. Pérez, 2003) se deduce la renuncia definitiva por parte de occidente de recuperar el territorio cristiano, ahora que la secunda Roma había caído en manos de los crueles turcos. Aparece entonces una argumentación lógica en la geoestrategia política o diplomática: si ya no podemos con el enemigo infiel, ahora hay que buscar la manera de mantener la frontera, la manera de tolerarlo (o de soportarlo, que es lo que significa etimológicamente el verbo tollere).

La maquinaria diplomática, no completamente parada hasta entonces, aceleró la marcha en pos de encontrar argumentos para la convivencia o, en un plano algo más abstracto, para la concordia.

Las relaciones comerciales que estaban manteniendo Venecia y Génova fueron una puerta para mantener y conseguir más pactos comerciales y políticos. Además, la presencia del islam en territorio hispánico era ya algo del pasado o se había convertido en un problema interno (el de los mudéjares y moriscos). A pesar de las denuncias de la violencia de los turcos, pocos meses después de la toma de Constantinopla el ortodoxo Jorge Escolario fue investido con el nombre de Genadio metropolita de Constantinopla por el sultán Mehmed II en persona en la basílica de santa Sofía (J. Gill 1959, 462). Además, los turcos respetaron las instituciones religiosas cristianas bajo su dominio (N. Iorga, 1935; F. Babinger, 1953; St. Runciman, 1963; I. Djuric, 1996). Irónicamente, la imposibilidad de acuerdo para la organización de una nueva cruzada contra el islam llevó al elogio de la disciplina moral y militar de los turcos (D.J. Vitkus, 1999). Las relaciones internacionales, pues, entre la Europa cristiana y el islam, ahora encabezado por la hegemonía del sultán turco-otomano Mehmed II, debían ir, no hacia el enfrentamiento con un enemigo más poderoso, no hacia la conversión de los infieles, no, en fin, hacia la destrucción del islam, sino hacia la negociación entre potencias (primordialmente desde Italia), hacia el establecimiento de relaciones diplomáticas, hacia el diálogo (O. de la Cruz - D. Álvarez, 2009).

Para aportar concordia al clima de relaciones con los turcos, los antecedentes literarios que se habían mostrado más tolerantes con el islam parecieron útiles, como eran los casos citados de Pedro el Venerable, Riccoldo de Monte Croce y Ramon Llull.

El mismo año de la caída de Constantinopla, Nicolás de Cusa escribe su De pace fidei. Se trata de un diálogo entre representantes de todas las 
naciones (griega, italiana, árabe, india, caldea, escita, francesa, persa, siria, española, turca, alemana, tártara, armenia, bohemia e inglesa). Los temas del diálogo religioso se organizan en tres niveles: la propuesta de un consenso de un punto de unión entre sus religiones (judaísmo, cristianismo e islam), sus dogmas y los rituales o sacramentos. Al segundo nivel el Cusano hace un esfuerzo dialéctico muy loable para conseguir esta concordantia ${ }^{4}$ entre las profesiones judías y musulmanas y los dogmas cristianos, a los cuales, sin embargo, no renuncia: Trinidad, encarnación, inmaculada concepción, la muerte de Cristo causada por los judíos, resurrección y redención, y naturaleza intelectual de la gloria. Hay que recordar que la concordantia no es exactamente lo mismo que 'el acuerdo' (fruto, por ejemplo, de una negociación y de ciertas renuncias o concesiones de las partes), sino más bien 'los puntos en común', es decir, en las doctrinas coincidentes entre las religiones. La concordantia es una búsqueda opuesta a la contrarietas (doctrinas o ideas contradictorias o insostenibles) y a la falsitas (doctrinas o ideas falsas). La concordia es, sencillamente, la con-cordia, es decir, el consenso de los sentimientos, de los afectos; se da cuando las voluntades (corda) de muchos se unen en aquello que constituye algo único, un fin común a todos ellos (S. Magnavaca, Léxico técnico de filosofia medieval. Buenos Aires, 2005, s.v. concordia) (O. de la Cruz - D. Álvarez, 2009).

Pero antes de proseguir con las ideas conciliaristas de Nicolás de Cusa (1401-1464) cabe remarcar la importancia de su De pace fidei (1454) y sus antecedentes. Teniendo en cuenta la tradición de literatura de refutación del judaísmo y del islam, la propuesta de Nicolás de Cusa supone un gran contraste, visto que la mayoría de los discursos pronunciados, entre los que habían unos cuantos en forma de diálogo (C. Cardelle de Hartmann, 2007 para los diálogos con el judaísmo), pretendían la refutación de la religión opuesta al cristianismo, en muchas ocasiones por medio de la ridiculización. Incluso los esfuerzos de objetividad aparecidos desde la primera mitad del s. XII por mano de Pedro Alfonso de Huesca y Pedro el Venerable, seguidos de los dominicos y franciscanos, que incorporaron el método de las fuentes directas para buscar en las fuentes del opositor los argumentos de refutación, no llevaron casi nunca al anhelo de concordia expresado por Nicolás de Cusa. Excepto, como hemos visto, en dos casos significativos: Riccoldo de Monte Croce y Ramon Llull, ambos estrictamente contemporáneos. Cabe recordar la

4 De pace fidei, 1: unam posse facilem quandam concordantiam reperiri, ac per eam in religione perpetuam pacem conueniendi ac ueraci medio constitui: poder encontrar una sola concordancia fácil y a través de ella concertar la paz permanente en materia de religión y establecerla por medio seguro (trad. propia). 
indudable influencia de Ramon Llull sobre el Cusano, dado que se conservan evidencias de que éste copió bastantes obras de Ramon Llull mientras estudiaba en París, de los que se conservan autógrafos o de su propiedad varios manuscritos (los mss. de Bernkastel-Kues Hosp. 37; 81; 82; 83; 86; 88; y el ms. de Praga UK, XXIII D 132 Lobk. 249)5.

El caso de Nicolás de Cusa, ciertamente, evoluciona como el de Ramon Llull: no debe dejarse de mencionar que, tras el celebrado De pace fidei, Nicolás de Cusa compone su Cribratio Alcorani (1462), con unos métodos de denostación del islam semejantes a la tradición dominica de Ramon Martí (c. 1230-1286) en su Pugio fidei, es decir, acudiendo a la fuente del adversario para demostrar la falsedad de sus dogmas. De hecho, entre las influencias directas de Nicolás de Cusa hay que mencionar el tratado elaborado por su amigo Dionisio el Cartujano, Contra perfidiam Mahometi (ed. P. Quentel, 1533, reed. 1908), en donde, con el mismo método de la Cribratio Alcorani, el Cartujano vacía la traducción latina del Corán elaborada por Robert de Ketton (1142-1143) para denostar al islam.

Junto a la nueva actitud de Nicolás de Cusa hay que considerar la de su amigo Juan de Segobia, al que insta, en una carta fechada en 1454, a acabar su traducción bilingüe del Corán (castellano-latín, junto a la versión árabe) para entregársela al Papa, en aquel momento Pío II, con el que también mantenía una estrecha amistad. En la misma carta, Nicolás de Cusa argumenta que:

Non est dubium medio principum temporalium, quos Teucri sacerdotibus praeferunt, ad colloquia posse perveniri, et ex illis furor mitigabitur et veritas se ipsam ostendet cum profectu fidei nostrae (R. Klibansky - H. Bascour (eds.) (1959), p. 97)

No hay que dudar que, por medio de los príncipes temporales, que los Teucros prefieren a los sacerdotes, se puede llegar al diálogo (colloquia), gracias al cual se verá reducido su furor (furor) y la verdad se manifestará por sí misma, para provecho de nuestra fe. (trad. propia)

En el fragmento citado hay dos elementos que debemos subrayar: la mención del furor de los turcos, palabra que, por tradición literaria, especialmente Séneca, remite a la locura (amentia) de quien tiene furor o ataque irracional. El Cusano, de manera interna con su amigo Juan de Segobia, mantiene el tópico de lo irracional en el islam, idea que no se permite expresar de ninguna manera en su De pace fidei. El segundo elemento es la referencia

5 Todos ellos pueden verse en red gracias al Raimundus-Lullus-Institut de la Univ. de Freiburg (Peter Walter, dir.), y a través de la página de Anthony Bonner:

http://orbita.bib.ub.es/llull/gent.asp?id=390 
a los turcos como Teucri (N. Bisaha 2004), es decir, a los teucros, uno de los antropónimos de tradición homérica para referirse a los troyanos. ¿Cómo? La asociación teucros/turcos tiene un origen incierto, pero aparece explicada como genialidad argumental en el humanista Giovani Mario Filelfo, cuando compone entre 1471-1476 su obra Amyris, un poema hexamétrico, en el que el sultán turco Mehmed aparece como descendiente de Príamo, inventando un juego etimológico que justifica la explicación de Turci como Teucri:

\section{(...) Phrygia nam gente parentes}

esse tuos, quis nescit adhuc? Cui cornea fibra est usque adeo immanis, tibi qui antiquissima regna audierit nunquam Troiae statuisse priores, maiorum proavos? Othman nam maximus ille quartus Ericthonio proavus fuit; ille relatus Chaldaeo quandoque solo, bellisque fugatus Persarum strepitu, Phrygiam superaverat oram, et Lyciam, Mysasque truces. Tandemque quievit cultus ut e caelo numen, quod quisque veretur. Othman gente satus, Priamique e stirpe relatus, tu genus es Priami, teque ornamenta sequuntur sanguinis invicti quondam, dein fraude remissi.

(Filelfo, Amyris I, 472-484)

Pues ¿quién desconoce todavía que en el prueblo frigio se hallan tus parientes? ¿Quién tiene todavía unas cuerdas (de lira) tan rígidas [cf. Pers., Sat. I, 47] y tan monstruosas, que nunca habías oído que los antepasados de Troya habían levantado unos reinos más antiguos, ancestros de los antepasados? Pues aquel gran Otmán [sc. el epónimo de los otomanos] fue el cuarto tatarabuelo de Erictonio [sc. del que proceden Teucro, Ilo, Laomendonte y Príamo]: éste, retirado en una sola ocasión contra los caldeos y huído de guerras por los jaleos de los persas, había llegado a la costa frigia, a Licia y a las salvajes tierras de Misa. Y al fin encontró alivio en los cultos hacia el numen del cielo al que cualquiera venera. Otmán engendró a su pueblo, conocido por la familia de Príamo: tú eres el origen de Príamo y te siguen los adornos de una antigua sangre invicta, después referida de manera fraudulenta (fraude) [es decir, explicado falsamente por la tradición (griega)]. (trad. propia)

$\mathrm{Y}$ es que Filelfo escribe el Amyris (por cierto, un neologismo latino derivado del turco para Emir) para su amigo Othman Lillo Ferducci, quien, estando relacionado familiarmente con miembros del poder otomano, le pide a Filelfo una composición de elogio al sultán. Un nuevo gesto de aproximación diplomática hacia el Levante otomano: la aparición de los nuevos turci restituyen justamente el lugar que ocuparon los teucri, después de que los griegos y los romanos les arrebataran de su lugar. Así, el sultán 
turco es un pariente lejano pero directo y legítimo del venerable Príamo, a pesar de que ello ha sido negado o esta información manipulada (fraude) por la tradición.

Junto al tándem Nicolás de Cusa y Juan de Segovia hay que mencionar al tercero, Silvio Eneas Piccolomini (1405-1464), nombre del papa Pío II (reg. 1458-1464) con el que ambos tienen una estrecha relación. Se le atribuye una Epistula ad Mahumetem, es decir, dirigida al sultán Mehmed II, aparecida en $1461^{6}$, sobre cuyo carácter apócrifo la crítica está de acuerdo. El texto, sin embargo, merece atención, pues los gestos de búsqueda de concordia son claros, una vez que los turcos se reconocen invencibles para los señores cristianos. Así, por ejemplo, en el libro III compara al sultán precisamente con el emperador Constantino, aunque la conocida Donatio Constantini (el documento que demostraba la delegación que hizo Constantino del poder temporal en manos del Papa), estaba comenzando a levantar dudas de autenticidad en aquellos mismos años. Menos conocida que la Epistula ad Mahumetem es también la apócrifa carta enviada por el sultán otomano Murad II (Morbisanus) al papa Pío II, con fecha 745 de la hégira/1444 d.C., que quiere presentarse, por lo tanto, como escrita años antes de la caída de Constantinopla y en el mismo año del nuevo envío de soldados contra los turcos, una de las últimas cruzadas. En ella, el sultán protesta contra el envío de los cruzados, pues, al contrario que los judíos, el musulmán es un pueblo inocente de la muerte de Cristo:

...deberetis neque Christianos, maxime Italicos, crucis charactere insignitos, inducere super nos: cum, secundum quod patres ante dixerunt nobis, populus noster Turcarum innocens fuerit mortis et iniuriae Christi uestri (...) Ac insuper admirari et dolere compellimur, quod surgunt Italici contra nos, cum latens amor nos incitet ad dilectionem ipsorum, eo quod ipsi et ipsorum magnalia et parentes a Troianorum singuine processerunt, quorum autorem fuisse scimus ueraciter Antenorem et Aeneam de sanguine Priami procreatos, in cuius locum ducturi sumus imperium in partibus Europae, secundum repromissiones a diis nostris, quas partes nostri habuissse noscuntur, et Troiam magnam intendimus restaurare et ulcisci sanguinem Hectoris ac Ilionis ruinam, nobis Graecorum imperium subiugando, et inuiriis deae nostrae Palladis factis eosdem punire in transgressorum haeredes [cf. v.gr. Virg. Aen. II, 183-191]. (Theodor Bibliander (1543), Machumetis Saracenorum principis eiusque successorum uitae..., [Basilea] t. III, p. 99-100).

6 Conocemos las ediciones siguientes: GLEI, R.F. - KÖHLER, M. (2001), Pius II Papa. Epistola ad Mahumetem. Einleitung, kritische Edition, Übersetzung, Bochumer Altertumswissenschaftliches Colloquium (BAC Band 50), Trier. - SANZ, F. (2003), Silvio Eneas Piccolomini. Carta a Mehmed II, Madrid. - TOFFANIN, G. (1953), Lettera a Maometto (Epistula ad Mahumetem), Napoli. 
No deberíais enviar sobre nosotros a los cristianos, sobre todo italianos, marcados con el signo de la cruz: puesto que, según lo que los ancestros nos transmitieron, nuestro pueblo turco fue inocente de la muerte y de la vejación de vuestro Cristo (...) Además estamos obligados a sorprendernos y lamentarnos de que los italianos vengan contra nosotros, cuando un amor escondido nos convida a estimarlos, ya que ellos, las cosas más magníficas y sus antecesores procedieron de la sangre de los troyanos, el iniciador de los cuales sabemos ciertamente que fue Antenor y Eneas, salidos de la sangre de Príamo, en lugar del cual tenemos que llevar el imperio hacia Europa, según las promesas de nuestros dioses, hacia aquellas partes que los nuestros saben que poseyeron, y pretendemos restaurar la gran Troya, vengar la sangre de Héctor y la destrucción de Ilión, sometiendo a nosotros el imperio de los griegos y castigar a los herederos de los criminales por las injurias que hicieron a nuestra diosa Palas Atena. (trad. propia)

Estos ejemplos en los que vemos gestos de aproximación al islam, sobre todo a partir de la victoria de los turcos sobre Constantinopla, irán aumentando en número con el transcurso de los años, aunque es bien cierto que el tono de referencia denigratoria sigue siendo sensiblemente alto. Durante todo el siglo XVI siguiente, además, van apareciendo en el panorama cultural europeo los primeros orientalistas, resultado del desarrollo de las cátedras de lenguas orientales aprobadas en el Concilio de Vienne de 1311. Entre ellos nos interesa destacar a Guillaume Postel y su relación con Theodoro Bibliander y su impresor Iohannes Oporinus, todos ellos coincidentes en compartir las ideas universalistas de la concordia mundi que, como hemos visto, ya se había gestado mucho tiempo atrás (V. Segesvary, 1978;O. de la Cruz, 2011 en prensa).

El francés Guillaume Postel Barentonio (1510-1581) debe situarse entre los primeros y mejores orientalistas. La obra más destacada para comprender su interpretación del islam es sin duda el segundo de los cuatro libros de su De orbis terrae concordia (Basilea, s.a. [1543-1544]), junto a los cuales debe leerse también su Alcorani seu legis Mahometi et Euangelistarum concordiae liber, Paris, $1543^{7}$, libro que fue publicado escindido del anterior ${ }^{8}$ por los motivos que resumimos a continuación: Los cuatro libros del De orbis terrae concordia, escritos en 1542, pretendían la demostración racional del cristianismo, poniéndolo en comparación y concertándolo con los principios

$7 \quad$ A partir de ahora Alcorani.

8 La misma opinión en M. Kuntz (1981, 44): "Postel decided against sending all the De orbis terrae concordia to Oporinus immediately, because he felt that his criticism of the 'Evangelists' whom he labels as 'Ceneuangelistae' in the fourth book might cause problems. Therefore he published that section of the work himself under the title of Alcorani seu legis Mahometi et euangelistarum concordiae liber in 1543". 
doctrinales entre las religiones del momento, judaísmo, cristianismo, islam y la reciente confesión protestante. Al ser rechazada al principio su impresión por la Sorbona, Postel hace imprimir el libro primero, en París en 1543, para poder divulgar su publicación en tela de juicio, es decir, a modo de circular. Buscando, pues, la manera de que su De orbis concordia saliera a la luz, Postel encuentra el ofrecimiento del impresor suizo Oporino, fuera del alcance de la necesaria aprobación de la Sorbona. Mas ante su amigo filoprotestante Oporino, Postel debe escindir del libro cuarto lo concerniente a las críticas al protestantismo, imprimiéndolo en París con el título Alcorani seu legis Mahometi et Euangelistarum concordiae liber.

La aceptación por parte de Oporino de imprimir el De orbis concordia de Postel es comprensible, dado que las críticas al islam que hace Postel en el libro segundo, en donde incluye numerosas citas alcoránicas traducidas del árabe por él mismo (H. Bobzin, 1995), concierta con la labor que le está ocupando en el mismo año de 1543 en el que Postel le solicita la impresión de su libro: y es que Oporinus estaba ocupándose de la impresión del monumental compendio de obras de referencia al islam dirigido por Bibliander, que incluía la impresión de la primera traducción latina del Corán elaborada para el abad de Cluny, Pedro el Venerable hecha en 1142-1143, hacía exactamente 400 años.

Si bien el De orbis concordia aparece publicado por Oporinus, pero sine anno, éste es comúnmente admitido en 1544, tras la aparición de la obra de Bibliander. Postel no era desconocido para Bibliander ni Oporinus: al imprimir la sura primera del Corán de Pedro el Venerable, habían incluído la traducción de la misma ofrecida por Postel en su Grammatica Arabica, publicada en París en 1539 o 1540. No en vano, el mismo Postel dará una explicación hermética al año de la publicación de su obra: cumple la profecía de que la ley de Mahoma desaparecerá cuando ésta sea expuesta públicamente por los cristianos, cosa que ocurrirá a los mil años. La fecha de 1543 coincidía, en los cálculos de Postel, con el milenario del nacimiento de Muhammad (F. Secret 1963, 97-98; 1962) $)^{9}$. La impresión de Bibliander demuestra que para Postel la traducción latina del Corán y los textos sobre los árabes elaborados para Pedro el Venerable (el corpus islamolatinum, cf. J. Martínez Gázquez 2011 y su web "islamolatina") no le eran desconocidos. Además, su método de análisis del Corán en el libro II de su De orbis concordia coinciden plenamente con el empleado por Nicolás de Cusa en su Cribratio Alcorani, texto que también recoge Bibliander.

9 La profecía viene dada en el manuscrito de G. Postel conservado en la British Library de Londres, ms. Sloane 1141, fol. 312 (dado por F. Secret 1963, nota 28). 
Su ordenada exposición doctrinal sobre el islam, manifiestamente racionalista, requiere, por lo tanto, haber tenido que vaciar previamente el texto coránico. Pero lo que quizás es nuevo en Postel y creemos que no ha sido suficientemente destacado, no es, pues, su mentalidad respecto al islam, que se ofrece en realidad bastante tradicionalista, sino el esfuerzo de concreción que ha hecho a la hora de trabajar por la concordia, es decir, el consenso de los corazones, de los afectos, un principio que es acorde con todo su pensamiento universalista (V. Segesvary 1978, 243-245). En las conclusiones del libro II del De orbis concordia (pp. 248), Postel compila los puntos doctrinales que, con el Corán en la mano, ha deducido que tienen en común el cristianismo y el islam (cum mussulmanis congressus). Además, según parece, el autor tradujo al árabe tales conclusiones: Primus cum mussulmanis congressus iam ab authore Arabice uersus, cui titulus arabice est "Omnium doctrinarum quae ad hominum excellentiam requirunt compendium".

[De orbis concordia, 248] In nomine Dei, misericordis, pii [basmala]. Laus Deo regi saeculorum [Q. 1, 1/2], potentissimo [Q. 33, 38], sapientissimo [cf. Q. 2, 27/29], optimo [Q. 5, 114], a quo omnia, per quem omnia et in quo omnia; et pax consortibus eius, et in ueritate quaerentibus eum; et clementia Dei et pax et misericordia sit super omnes homines. Amen.

Ante rem omnem praecessit causa uel causae eius, quoniam nulla res seipsam creat. Quare ante res omnes est Deus summus [Q. 19, 21], super omnia potens [Q. 2, 19/20]. Hunc orbem et mundum creauit Deus [cf. Q. 2, 20/22] excelsus in laudem suam [cf. Q. 1, 1/2], hominum utilitatem [cf. Q. $3,66 / 63$ ] et in utramque simul. Haec tria sunt fines unus seu causa finalis mundi.

Homo creatus est in laudem Dei, innocentiam et mundiciem sui et in charitatem proximi, opusque est ut haec tria sint in omni opere bono in re una; quoniam non est possibile ut sit opus bonum sine his tribus.

Res omnis est aut a manu Dei [Q. 3, 66/73] aut a sapientia et arbitrio hominum [cf. Q. II, 254/253] aut fortunae potentia. In potentia Dei inmediate sunt omnia, sed praecipue aeternitas et essentia, coelum, stellae, alteratio, motus, quies, ordo naturalis et quatuor naturae, uidelicet ignis, aer, aqua, terra, et quae ex illis nascuntur.

Homo uero cum prudentia et ratione reperit radices et principia rerum non naturalium, et inter tractandum exposuit in scientiam et artem.

A casu autem sunt ea quae accidunt, quibus non est similitudo cum opere Dei aut hominum [cf. Q. 2, 20/22], sicut sunt fortuita et accidentia non naturalia aut diuina, et res omnis, cui non est causa in natura; et in summa omnes perturbationes huius uitae et infoelicitatem eius uocant opus fortunae. Est autem scopus et finis Dei ut adducat hominem cum fide et certitudine in necessitatem suam et utilitatem rerum necessarium et in cognitionem sui et agnitionem Dei, ut inde detur fides hominibus ut fiat homo sanctus cum uirtute in dilectione boni summi, et ut post hanc uitam cognoscat causam rerum omnium in Deo summo. Punctus autem ad quem collimare homo 
debet est [cf. Q. 1, 5/6], ut soletur homines caeteros afflictos et necessitate pressos, ut iuuet diuites et pauperes, noceat nemini, uiuat ut illum iubent praecepta legis diuinae et humanae, et habitet in hoc mundo ut in diuersorio, ut cui mundus est unica ciuitas, si sapiat. Scopus fortunae nullus est, quoniam ex arbritio nil agit.

En el nombre de Dios, misericordioso, pío. Alabanza a Dios, rey de los siglos, el más potente, el más sabio, el mejor, del Cual <procede $>$ todo, por el Cual <existe > todo y en el Cual <se contiene> todo; y paz a Sus seguidores y a los que Le buscan en la verdad; y sea la clemencia y la paz y la misericodia de Dios sobre todos los hombres. Amén.

Antes de cualquier cosa precedió Su causa o causas, ya que nada se crea a sí mismo. Por ello, antes de todas las cosas Dios es el máximo, potente sobre todo. Dios excelso creó este orbe y mundo para su alabanza, la utilidad de los hombres y para una y otra cosa a la vez. Estas tres cosas son un único fin o causa final del mundo.

El hombre ha sido creado en alabanza de Dios, en la inocencia y limpieza de Sí y en amor hacia los demás, y es obligación que estas tres cosas estén en toda obra buena en una sola cosa; porque no es posible que exista una buena obra sin estas tres.

Toda cosa existe bien por orden de Dios, bien por sabiduría o arbitrio de los hombres o bien por la fuerza del azar. En la potencia de Dios están a la vez todas las cosas, pero principalmente la eternidad y la esencia, el cielo, las estrellas, la alteración, el movimiento, la calma, el orden natural y las cuatro naturalezas, es decir, el fuego, el aire, el agua y la tierra, y lo que de ellos nace.

El hombre, con la prudencia y la razón, encuentra las raíces y los principios de las cosas no naturales, y las explica con el conocimiento y la técnica.

Por suerte hay aquellas cosas que ocurren, respecto a las cuales no hay semejanza con la obra de Dios o de los hombres, tales como las cosas fortuitas y los accidentes no naturales o divinos, y toda cosa para la que no hay causa en la naturaleza y, en resumen, llaman obra de la fortuna a todas las perturbaciones de esta vida y a su infelicidad. Así pues, es meta y fin de Dios conducir al hombre con fe y certeza en su necesidad y utilidad de las cosas necesarias, en su conocimiento y reconocimiento de Dios, para que entonces le sea dada la fe a los hombres con tal que se haga un hombre santo con la virtud en el amor del Bien máximo, y para que reconozca tras esta vida la causa de todas las cosas en el Dios máximo. El punto que debe alcanzar el hombre es que se allegue a los demás hombres afligidos y presos de la necesidad, que ayude a los ricos y a los pobres, no perjudique a nadie, viva como le mandan los preceptos de la ley divina y humana y viva en este mundo como en una residencia, de manera que para él el mundo es una única ciudad, si lo supiera. Ninguno es el fin de la fortuna, porque a partir del arbitrio no ocurre nada. (trad. propia)

Como vemos en las notas que hemos añadido al texto, se trata de una compilación de dogmas aceptables al cristianismo y al islam tomados en parte de lugares alcoránicos. Sin embargo, tales conclusiones le parecieron 
insuficientes, ya que, a este congressus Postel tuvo que añadir la aceptación necesaria de la Trinidad y de Jesucristo, los dos puntos que tradicionalmente separaban el cristianismo del islam: (De orbis concordia, 248-249): Continet uero probationem trinitatis compendiariam, laudes Iesu Christi et Euangelii ex Alcorano decerptas et praecipua eius persuasionis errata. Si bien, tras esta exposición, Postel pudo encontrar y añadir una compilación de lugares alcoránicos y textos islámicos que demostraban laudes Iesu Christi (De orbis concordia, 252-256) y laudes Euangelii (De orbis concordia, 256-258), no pudo sin embargo encontrar lugares afines a la demostración de la Trinidad, que tuvo que demostrar racionalmente con principios lógicos, pero no alcoránicos: mundi uniuersi et rerum harmonia in quaternario posita, unde lux maxima cognoscendae trinitatis oritur (De orbis concordia, 259-261). Postel había topado con el mismo muro con el que había topado la tradición: la imposibilidad de la Trinidad para el islam.

En conclusión, y valga también como conclusión general, los esfuerzos de Postel por ofrecer una concordia mundi entre religiones fueron notables, pero sus obras demuestran una instalación en la superioridad de la verdad cristiana que, según la experiencia de la literatura de controversia tradicional, condenaba de antemano al fracaso su sincero intento: el sueño de una ciuitas mundi también se le había presentado a Ramon Llull y a Nicolás de Cusa. Pero Postel despertaba de él al llegar a la concordia respecto al tema de la Trinidad, dogma que seguía resistiéndose a ser aceptado por todas las religiones. Una vez más, su nueva traducción del Corán, aun con voluntad de ser muy precisa y servir, con ello, a no contribuir a la distorsión de las interpretaciones, no pudo llegar a conseguir el fin deseado.

\section{APÉNDICE. LA ACTUALIDAD}

Todavía el Concilio Vaticano II (sesión del 28 de octubre de 1965, n. 3) declara:

La Iglesia mira también con aprecio a los musulmanes que adoran al único Dios, viviente y subsistente, misericordioso y todo poderoso, Creador del cielo y de la tierra, que habló a los hombres, a cuyos ocultos designios procuran someterse con toda el alma como se sometió a Dios Abraham, a quien la fe islámica mira con complacencia. Veneran a Jesús como profeta, aunque no lo reconocen como Dios; honran a María, su Madre virginal, y a veces también la invocan devotamente. Esperan, además, el día del juicio, cuando Dios remunerará a todos los hombres resucitados. Por ello, aprecian además el día del juicio, cuando Dios remunerará a todos los hombres resucitados. Por tanto, aprecian la vida moral, y honran a Dios sobre todo con la oración, las limosnas y el ayuno. Si en el transcurso de los siglos surgieron 
no pocas desavenencias y enemistades entre cristianos y musulmanes, el Sagrado Concilio exhorta a todos a que, olvidando lo pasado, procuren y promuevan unidos la justicia social, los bienes morales, la paz y la libertad para todos los hombres.

\section{BIBLIOGRAFÍA CITADA:}

F. Babinger (1953), Mehmed der Eroberer und seine Zeit. Weltenstürmer einer Zeitenwende. München (trad. it. Maometo il Conquistatore e il suo tempo. Torino, 1957).

P. Bádenas de la Peña - I. Pérez Martín (eds.) (2003), Constantinopla 1453, mitos y realidades, CSIC-Madrid.

Th. Bibliander (1543), Machumetis Saracenorum principis eiusque successorum uitae ac doctrina, ipseque Alcoran... Haec omnia in unum uolumen redactae sunt opera et studio Theodoro Bibliandri, t. 1-3, ed. Johannes Oporinus, s.l. [Basileae]; s.l. [Basileae] 1550²; Zurich, $1556^{3}$.

H. Bobzin (1995), Der Koran im Zeitalter der Reformation. Studien zur Frühgeschichte der Arabistik und Islakunde in Europa, Beirut.

N. Bisaha (2004), Creating East and West. Reanissance Humanists and the Ottoman Turks. Univ. of Pennsylvania, Philadelphia.

A. Bonner (ed.) (2001²), Ramon Llull, Libre del gentil e dels tres savis, NEROL II, Palma de Mallorca.

C. Cardelle de Hartmann (2007), Lateinische Dialoge 1200-1400. Literaturhistorische Studie und Repertorium, Leiden-Boston. I. Djuric (1996), Le crépuscule de Byzance. Paris.

O. De la Cruz Palma (2008), "The human realm", en A. Fidora-J.E. Rubio, Raimundus Lullus. An Introduction to his Life, Works and Thought, CCCM 214, Turnhout, pp. 413-459.

O. De la Cruz Palma - Daniel Álvarez Gómez (2009), "Die Rhetorik der Eintracht bei Nilolaus von Kues (1401-1464)", B.F.W. Springer - A. Fidora (eds.), Religiöse Toleranz im Spiegel der Literatur. Eine Idee und ihre ästhetische Gestaltung, Zürich-Münster, 93-102.

O. De la Cruz Palma (2011, en prensa), "Los primeros orientalistas frente al islam: la traducción latina del Corán de Guillaume Postel", en IX Congreso de la Sociedad Española de Ciencias de las Religiones (SECR), Madrid, 13-15 de octubre de 2011.

E. du Meril (1847), Poésies populaires latines du Moyen Age, Paris (reimpr. anastática, Genève, 1977): Gautier de Compiègne, Otia de Machomete, pp. 368-415.

J. Gill (1959), Il Concilio di Firenze, Firenze. 
R. Glei (1985), Petrus Venerabilis. Schriften zum Islam, col. Corpus Islamochristianum, Altenberge, pp. 30-224.

L. Hagemann (1986), Nicolás de Cusa Cribratio Alcorani (1462) [ed. crítica de L. Hagemann, Nicolai de Cusa Opera omnia iussu et auctoritate Academiae Litterarum Heidelbergensis ad codicum fidem edita, vol. VIII, Hamburg; trad. al alemán de R. Glei; ed. latina y trad. al francés Le Coran tamisé de H. Pasqua, Paris, 2011]

N. Iorga (1935), Byzance après Byzance, Paris (1971²).

R. Klibansky - H. Bascour (eds.) (1959), Nicolás de Cusa De pace fidei (1453). Epistula ad Ioannem de Segobia. Hamburg [ed. crítica de R. Klibansky H. Bascour, Nicolai de Cusa Opera omnia iussu et auctoritate Academiae Litterarum Heidelbergensis ad codicum fidem edita, vol. VII, Hamburg].

M. L. Kuntz (1981), Guillaume Postel, Prophet of the Restitution of all things. His life and throught, Boston.

M. J. Lacarra (dir.) (1996), Pedro Alfonso de Huesca. Diálogo contra los judíos, Instituto de Estudios Altoaragoneses, Huesca.

A. Manetti (ed.) (1978), G.M. Filelfo, Amyris, Bologna.

Migne, PL 171, cols. 1343-1366: Embrico de Mainz, Carmen de fraudibus Mahumetis.

J. Martínez Gázquez (2007), La ignorancia y negligencia de los latinos ante la riqueza de los estudios árabes, discurso leído el día 8 de febrero de 2007 en el acto de recepción pública en la Real Academia de Buenas Letras de Barcelona.

J. Martínez Gázquez (2011), "Islamolatina: estudios sobre el corpus islamolatinum (1142-1143) y literatura de controversia islamo-judeocristiana", C.E. Prieto Entrialgo (ed.), Arabes in patria Asturiensium, vol. 3, 171-190.

J. Martínez Gázquez (dir.) (2007-): Islamolatina: [http://hipatia.uab.es/ islamolatina].

A. Pertusi (ed.) (1976), La caduta di Costantinopoli. vol. 1: Le testimonianze dei contemporanei; vol. 2: Leco nel mondo, Fondazione Lorenzo Valla, Roma.

Picco della Mirandola (1496 ${ }^{1}$, póstumo), Oratio Ioannis Pici Mirandulae de hominis dignitate, Bolonia [para el texto latino con trad. italiana G. Tognon - E. Garin (eds.), Discorso sulla dignità dell'uomo. Brescia, 1987; para la trad. catalana, Antoni Seva, Discurs sobre la dignitat de l'home, Public. Universitat de València (PUV), 2004].

G. Postel (s.a. [1543-1544]), De orbis terrae concordia libri quatuor multi iuga eruditione ac pietate referti, quibus nihil hoc tam perturbato rerum 
statu uel utilius uel accommodatius potuisse in publico edi, quiuis aequus lector iudicabit. Gulielmo Postello Barentonio mathematum in Academia Lutetiana professore regio authore. Adiectae sunt quoque annotationes in margine a quodam pio atque erudito uiro, ne delicatioris palati aut iniquioris etiam iudicii aliquis ut sunt fere hodie quam plurimi offenderetur. Proinde ut pectore candido acciperet, quae in Ecclesiae missere adeo afflictae utilitatem scribuntur, Lector uelis, per Christum et animae tuae salutem obtestatum te uolumus. Singulorum librorum argumenta sequenti mox pagina, capitum uero ac rerum cathalogum ad libri calcem reperies. Cum Caesaris Maiestati et Christianissimae Galliarum regis priuilegiis ad quinquenium, s.l. [Basileae, ed. Ioannes Oporinus].

G. Postel (1543), Alcorani seu legis Mahometi et Euangelistarum concordiae liber, in quo de calamitatibus orbi Christiano imminentibus tractatur. Additus est libellus de uniuersalis conuersionis, iudiciiue tempore, et intra quot annos sit expectandum, coniectatio ex diuinis ducta authoribus ueroque proxima. Parisiis, excudebat ipsi authori Petrus Gromorsus sub Phoenicis signo iuxta scholas Remenses, Paris, ed. Petrus Gromorsus.

P. Quentel (ed.) (1533), Doctoris Esctatici D. Dionysius Cartusianus, Opera omnia XXXVI, pp. 231-442 (reed. opera omnia vol. IV, Tournai, 1908).

F. Secret (1962), "Guillaume Postel et les études arabes à la Renaissance", Arabica 9/1, 21-36.

F. Secret (1963), "Lhermeneutique de Guillaume Postel", Archivio di Filosofia. Umanesimo e Ermeneutica, 91-45.

F. Secret (1970), Bibliographie des manuscrits de Guillaume Postel, col. Études de philologie et d'histoire 16, Genève.

V. Segesvary (1978), L'Islam et la Réforme. Étude sur l'attitude des reformateurs zurichois envers l'Islam (1510-1550), Lausanne.

John Tolan (2007), Le Saint chez le Sultan: la rencontre de François d'Assise et de l'Islam. Huit siècles de'interprétation, Paris.

D.J. Vitkus (1999), "Early Modern Orientalism: Representations of Islam in Sixteenth and Seventeenth-Century Europe", en Michael Frassetto David R. Blanks, Western Views of Islam in Medieval and Early Modern Europe. Perception of Other. New York, 207-230.

A. Zannini (2009), Venezia città aperta. Gli stranieri e la Serenissima XIV-XVIII sec., Venezia. 